\title{
A named clinician must be central to orthodontic care
}

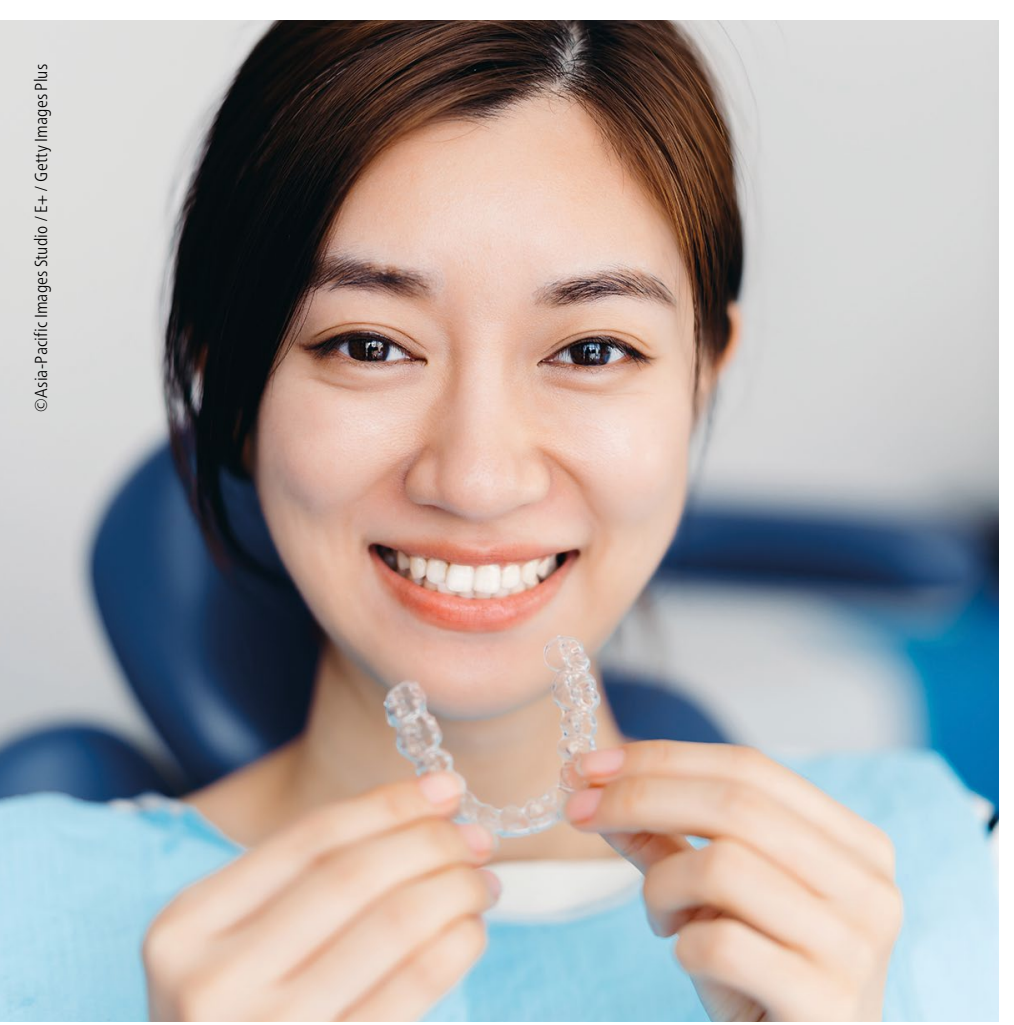

Knowing the name of the clinician who provides your orthodontic treatment should be a fundamental right, according to Dr Asif Chatoo, an orthodontist who founded the first clinic in the UK dedicated to lingual orthodontics.

Dr Chatoo's comments are made following publication of a statement from the General Dental Council (GDC) ${ }^{1}$ as well as the 2020 review of the Dental Complaints Service (DCS), ${ }^{2}$ which highlight the worrying growth in 'direct-to-consumer' orthodontics.

The DCS annual report reveals that the majority of complaints by patients in 2020 related to perceived failure of treatment (85\%), with most arising from treatment with removable orthodontic appliances. Of concern to Dr Chatoo is that a case study in the report reveals the patient did not know the full name of the clinician who wrote their treatment plan. This meant that they had no one to turn to with their concerns or questions about their treatment.

The case study described how, following treatment, the patient complained to the company who provided the aligners because they could see no difference in their teeth. Initially, the company would only offer another course of treatment involving a second finance plan.

Fortunately, the DCS intervened and the company cancelled the finance agreement with the patient, who declined a second course of 'remote' orthodontic treatment.

Dr Chatoo said: 'Several things about this case study concern me. I am shocked that initially the company declined to share the name of the clinician who provided the treatment plan. Without the intervention of the DCS, the patient would not have had a refund and their credit rating might have been jeopardised due to the finance agreement not being cancelled. This highlights the risk of an arrangement with an online company as opposed to with an individual clinician or practice.'

In its statement, ${ }^{1}$ the GDC stresses that patients must know the full name of the dental professional responsible for their treatment and be able to make direct contact with that person if they should need to.

Dr Chatoo said: 'I am glad that the GDC and the DCS have highlighted the questions patients need to ask before they order aligners online. For all patients, knowing the name of your clinician should be a right.

'Communication between clinician and patient is critical to the provision of orthodontics and must not be lost in the rush to embrace innovation and remote technology?

\section{References}

1. General Dental Council. GDC Statement on 'direct-to-consumer' orthodontic treatment. Available at: https://www.gdc-uk.org/information-standards-guidance/ standards-and-guidance/gdc-guidance-for-dental-professionals/direct-toconsumer-orthodontics/gdc-statement-on-direct-to-consumer-orthodontictreatment (accessed July 2021).

2. Dental Complaints Service. Dental Complaints Service Review 2020. 19 May 2021. Available at: https://dcs.gdc-uk.org/about/publications (accessed July 2021). 